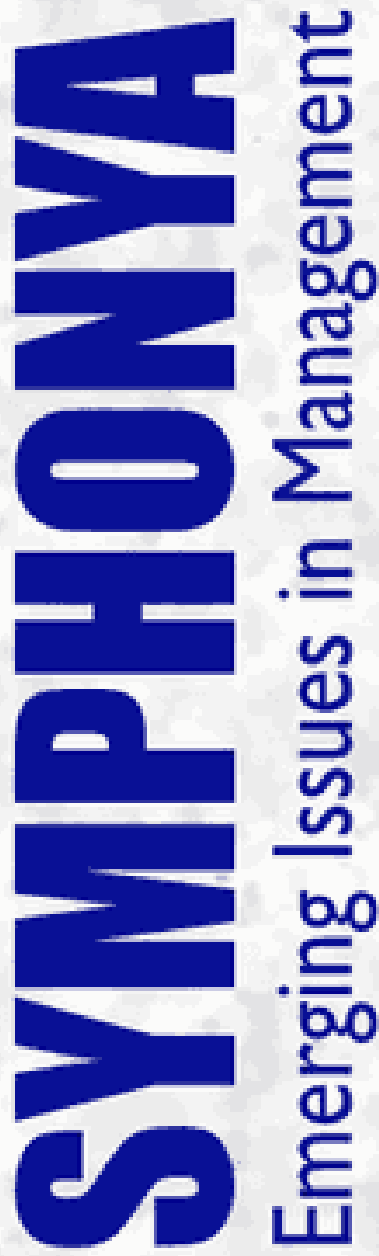

Indexed by

RePEe

te CABELL'S LIST

MOER

SCIrUS

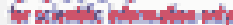

2011

Issue 2
ISTEI - UNIVERSITY OF MILAN - BICOCCA

\section{Global Cities and Knowledge Management - 2}

- OUMERTURE

Silvio M. Brondoni

University of Milan-Bicocca

- GROWTH CONSUMPION AND KNOMFDGE CIIES

Riccardo Cappellin

University of Rome-Tor Vergata

- WHIOHAUTUE? STRATEGICVSIONS FORAMEPICAN CITES

Raffeella Nanetti

Uniersity of lllinois at Chicago

- LAPGE CITES, NTANGIBLE CONSUMPIONAND KNOMEDGE PROOUCTION

Lara Penco

University of Genoa

- CONIEMPOPAFYART FRMSAND

VALUE CPEATION NGLOBAL CITES

Federica Codignola

University of Milan-Bicocca

- ASSESSNGUFBANEMRONMENTAL MANAGEMENTPPACTICEWTH ASCALARAPFPOAOH.THESHANGH CASE

WeiTu

Georgia Southern University

- WORID CIIES, NATIONSTATES AND GLOEAL COMPEIIION

Flavio Gneochi. Luca Bisio

Uniersity of Milan-Bicocca 


\title{
Contemporary Art Firms and Value Creation in Global Cities
}

\author{
Federica Codignola*
}

\begin{abstract}
Culture is increasingly important in the contemporary processes of economic value creation, and cities are able to generate urban requalification processes by enhancing the level and complexity of cultural intervention. Recently, these strategies have focused increasingly on contemporary art, and specifically on contemporary artistic firms that can stimulate a significant amount of original knowledge production in global cities.
\end{abstract}

Keywords: Global Cities, Contemporary Artistic Firms, Urban Regeneration, Knowledge Production, Culture

\section{The Role of Cultural Firms in the Development of Global Cities}

\subsection{Cultural Firms and their Impact on the Economy of the City: the Theoretical Perspective}

Recently, economic literature has dedicated a great deal of attention to the field of artistic-cultural assets, activities and firms. The many studies that have contributed to theoretical analysis in recent years have adopted new interpretation backgrounds that refer to tools from the sphere of economic and corporate management disciplines. This has underlined the fact that the cultural and artistic world, as a source of economic and social growth, constantly needs to raise its profile. The growing number of studies of the economics and management of cultural and artistic firms is certainly one effect of the cuts to investment in culture that have forced institutions to introduce evaluation methods designed to select the allocation of these resources. Another explanation comes from the fact that operators in this sector seem to be oriented to market-driven logics in order to diversify activities and to extend the sources of funding which can consider both the public sector and the needs of new stakeholders. This is why cultural enterprises have had to come to terms with a management logic that could strengthen their strategies and tools. Studies in this field can be broken down into four main areas: the 'sector' (focussing on museums on one hand and on performing arts on the other): the 'process' (focussing specifically on the particular functions or processes of the

* Assistant Professor of Management, University of Milan-Bicocca (federica.codignola@unimib.it)

Edited by: ISTEI - University of Milan-Bicocca

ISSN: 1593-0319

Codignola Federica, Contemporary art Firms and Value Creation in Global Cities, Symphonya. Emerging Issues in Management (www.unimib.it/symphonya), n. 2, 2011 
organisations, such as marketing or fundraising); the 'performance' (in which the focus of attention is the analysis of systems to measure results in terms of quality, management control, customer satisfaction, etc.); and the 'relations' (studying links and networks between specific organisations such as museums). These studies have evolved towards very different targets, although there is still no proper theoretical framework. This leads to an area of reflection in which the economic theory of culture intercepts and blends with corporate (or managerial) economic theory. In these terms, art and culture could be analysed as sources of economic value creation in benchmark territorial environments such as the town. In this article, we aim to examine the relationship between contemporary artistic firms operating in an urban environment (museums, galleries, festivals, biennials, fairs) and economic value creation. To this end, we aim to adopt a transverse interpretative approach, in other words without lingering on a theoretical distinction between profit-making or no-profit cultural firms, as this would inevitably limit our considerations. In this case, the elements of continuity common to the two types of firm are more interesting: we wish to propose a unitary analysis which, although aware of the existence of objective differences, can start from the assumption that it is possible to take advantage of strategies and management tools belonging to corporate literature, in a strictly cultural context. This makes it possible to talk about a 'cultural enterprise' even if, in specific terms, these entities differ widely and can, and must, be analysed on the basis of these differences. The other focal point of the perspective adopted depends on the fact that these firms deliver a very complex type of service, because they belong to the cultural sector. A museum, an art gallery, a festival or a contemporary art biennial offer a type of product that supplies a service to the purchaser or consumer (in the case that the service offered is free of charge), or a group of basic services that refer to the organisation's core activity, as well as other types of secondary and additional services. One of the basic elements ascribable to this type of service company is the intangibility of the immaterial content of the service, a topic that we will subsequently address in greater detail.

\subsection{The Tradition Method of Evaluating the Economic Impact of Cultural Firms}

The traditional method used to evaluate the economic impact of cultural and artistic firms includes the salaries of the personnel of the organisations, the purchase of goods and services by them, the induced effects (based on the purchase by the customers of cultural firms in the local context of goods and services deriving from the outside world) and derivatives (local subjects that profit from the presence of the cultural firms). In fact, with respect to the economic profile, the impact of the activities performed by a cultural enterprise in a region or, in this case, in a town or city, may have numerous origins. First of all, in terms of its 'contribution'; this may be direct if it regards the flow of wealth towards its internal professional skills, which, in turn, are intrinsically tied to the territory they belong to. Indirectly, on the other hand, the contribution that cultural firms make to the city or territory they belong to may derive from other factors such as: external supply relations; flows of wealth activated by a cultural firm that multiply expenditure, 
with a vaster economic impact; the firm's artistic-creative value as an incentive to the creation of a stronger cultural cluster, thanks to the arrival of other firms and the attraction of external investment. The cultural firm may, however, develop a capacity for attraction outside the local context, for example by attracting new flows of national and international tourism which inevitably impact on the development of an economic return, related to the services and goods offered by the commercial enterprises in the area. Starting from this element, it is easy to understand the concept and function of what literature calls 'creative cities': places where there is a significant agglomeration of social and creative organisations and facilities, from which the effect of the firms, cultural assets and activities on the economic and social results of a town emerges clearly. The cultural firm may also determine an indirect economic impact in relation to all the operators who collaborate with it, and may, similarly, represent an induced impact for all the individuals and organisations which can take advantage of the flows of wealth generated by its presence, by exploiting the services and goods delivered by the cultural enterprise.

The tourist who visits a particular city to see a given exhibition, festival or museum, will transfer additional economic resources to other local enterprises such as hotels, restaurants, transport, the high street, craft sector, etc.

The presence of the cultural firm also has other benefits for the territory: for example the financial resources that the entities performing activities in favour of or in the region of the firm will spend themselves; or the wealth produced by the firm that returns to the public sector. And finally, it may be useful to observe another group of intangible benefits (due to the presence of the cultural enterprises in the place where they operate). If on one hand the population in the area can take advantage of a higher cultural level, on the other hand this benefit can regard a city's renown and image, thus impacting on its identity.

\subsection{Contemporary Art Firms, Competitive Advantage of the City and Value Production}

If we refer to the specific territorial context of the city and its system of enterprise we have to consider Porter's concept of local clusters (Porter 1998), which may be analysed with regard to the economic context of culture. Clusters based on material resources may acquire an artistic and cultural value when they produce consumer goods, in other words when, as they do today, these goods have acquired greater symbolic significance and a broader aesthetic dimension in their relations with consumers. In addition to which we have to consider the fact that today, in our cities, the concentration of traditional artistic and cultural sectors has expanded qualitatively and quantitatively: the growing number of contemporary art shows, museums, etc., has led these firms to specialise, both horizontally and vertically. We therefore find all the elements typical of systematic aggregation, in which specialist firms relate and interact. 
$\square$ As a result, a city may acquire the identity of a cluster based on the dominant concept of immateriality because it is essentially qualified by particular elements such as culture and art (Scott, 2000), particularly contemporary art.

A city's competitive advantage is therefore the result of existing relations between different entities and organisations which, in order to acquire competitive advantage, may exploit the network relations with distinct entities, following mechanisms and rules based on coordination and cooperation. Relations between cultural firms operating in an urban area produce economic value. This is generated on one hand by the relations and interdependence between entities in the system, and on the other by knowledge creation and transfer processes.

$\square$ The sum of any city's assets includes its artistic assets which, as a qualifying feature, have the uniqueness and capacity to be associated with a 'potential flow of services' (Throsby, 2001).

In turn, these assets and services must be developed and managed so as to boost the artistic and cultural assets of the urban area. In other words, a contemporary art gallery can perform the functions of production and distribution simultaneously: on one hand, by conserving the works and exhibiting them to visitors or consumers it provides a distribution function, on the other it may provide a productive function, by offering a supplementary educational service, a cycle of seminars or even additional assets like a catalogue sold in its bookshop, etc. At the same time, the gallery may extend its offer/collection by purchasing new works, which increase the sum of the artistic assets in the city, and these, in turn, acquire more value from this type of enterprise. So in a way artistic assets represent a type of intangible consumption because what is consumed thanks to these firms is an experience (which impacts on the city's knowledge production). But contemporary art firms are also in touch with other types of firms belonging to the same urban context, and may develop or strengthen their respective products in a form of mutual involvement. In the contemporary art market, every city that meets the conditions mentioned above will incorporate a widespread system of entities exchanging value: between the contemporary art firms, between contemporary art firms and the human capital in the region, between contemporary art firms and the local system producing goods and services (a festival, an event or a museum may attract visitor flows to the city from outside so that they may potentially exploit other local goods and services), between contemporary art firms and local authorities, and between local contemporary art firms and national or international businesses.

\subsection{Relations and Value Creation Systems}

In order to observe the relations between contemporary artistic firms and local companies producing goods and services, we must assume that contemporary art assets, and the related firms, represent a strong attraction for tourism. For this reason, strategic relations are forged between art firms and operators in the tourism sector, based on a system of mutual collaboration, whose goal is to achieve 
competitive advantage: creating integrated services or a common communications strategy means collaborating towards the same goal to attract demand flows. Contemporary art firms can refer to local companies that are simply manufacturers of goods, creating systems of collaboration with them to achieve innovation: in the case of a gallery or museum, establishing a collaborative relationship with a firm that specialises in technology, for example, may lead to the creation or development of a highly innovative exhibition. Another form of relationship (whose goal is the creation of value) between contemporary art firms and local businesses, can be found in the field of industrial organisations. These have recently adopted a model of integrated communication that exploits a range of tools and leverage in a synergetic, consistent approach, working towards a system of heterogeneous publics inside and outside the business itself. The purpose of this integrated corporate communication is to create and strengthen the organisation's identity, while disseminating its image among the interested public. This can be done in various ways that range from the sponsorship of contemporary art events to the creation of a corporate art collection, etc. In the context of systems of cooperative relations, these may also evolve locally between several contemporary cultural firms: vertically, between the players in the contemporary art scene, and horizontally between clusters of homogeneous art firms, such as museums or galleries. These systems of cooperative relations can therefore create value and advantageous results through the combination of resources that are complementary in terms of: increased appeal, the creation and development of complex events, and innovative projects designed to strengthen the image. What is more, the aggregate coordination of specific activities such as the supply of goods and services by external suppliers may raise the level of overall efficiency and, still from an overall perspective, the services offered by these aggregate systems may be boosted significantly. Relationships of value in an urban context can therefore be amplified if the system of artistic and non-artistic firms incorporates a high level of synergies, in other words, if the players are highly involved in cooperative relationships and interdependence. The presence of a close-knit, visible network of businesses allows the city to take advantage in terms of: the expansion of its own knowledge production circuit; the simplification of the process of legitimation of these corporate systems with the public authorities; greater recognition and appeal for local or outside businesses. In this regard, contemporary art firms operating in a city can create cooperative relations with businesses from outside the area, which are similar or manufacture complementary goods and services. As a result, and thanks to the support of the new technologies that favour interaction and cooperation between these parties, additional channels may be developed to transfer knowledge from inside the city to the outside world and from the outside world to the city, boosting quantity and quality.

$\square$ As a result, contemporary art firms can encourage this exchange at a more complex level. i.e. the relationship between the local environment and the global environment. For example, when a local business decides to set itself global strategic goals it means that it will project the individual activities in its chain of value towards an international context, in which it will be forced to distinguish itself if it 
wants to excel, and the same applies to the relevant local context. Because of globalisation, the latter will have to compete with other local contexts.

We must however underline that the local context will only be able to develop a competitive advantage for the firms that operate there if it is able to compete on the same level with other local contexts. A local business will only excel if the local context is able to interact with a global system for the creation, transfer and use of knowledge. For a contemporary art firm, distinguishing itself can therefore mean maintaining strong local roots, but at the same time opening up to the global scene so that both dimensions can profitably blend and thus create value.

\section{The Value of Contemporary Art Firms in the Regeneration of the City}

\subsection{The Intangibility of Consumption and the Added Value of Contemporary Art Firms}

Today firms find they have to urge individuals to consume products that no longer meet primary needs but other kinds of requirements, mainly symbolic, related to their individual character. From this perspective we are able to understand the strategic importance of contemporary art firms which can help to boost a city's economic value. This obviously means that a similar type of urban development must be based on a long-term view and consistent strategy. In order to effectively address a market made up of such heterogeneous groups of interlocutors, stakeholders and consumers, firms must embody strong distinctive values, creating and managing differentiated means of communication that are market-oriented. One indispensable condition for effective urban investment in the contemporary art scene is that the project and the strategy behind the investment must be consistent with the identity of the territory in time. The reason for the presence of these firms in the city is not only to amplify financial resources or to reinforce its image; it must transform these firms into interlocutors that are conscious of their position and their cultural objectives. Contemporary art firms can thus represent a valid strategic choice to innovatively create competitive advantage in a market reality as complex as the one today. It would therefore be possible to create a fruitful dialogue between the city and the art firm, through which to acquire indications that are strategically effective, acquiring renown and added value among increasingly complex and diversified publics.

The need for aggregation between firms in the contemporary art scene becomes essential in markets that change so suddenly. As globalisation increases, the local concentration of new opportunities at various levels also increases: there may be several causes, but the weakening role of the state as the sole protagonist of economic policy and the opening up of competition space in areas that were once strongly conditioned, are among the most important. 
The territories and cities have expressed different development trends, activating tangible resources on one hand and intangible resources on the other, both striving towards significant cultural choices. Contemporary art as a tangible resource (assets, firms, infrastructure, etc.) and intangible (the intangible component linked to contemporary works of art, the creativity and similar skills in the region), can now represent a fundamental component of every urban development model. If the character of the contemporary art product or the contemporary creativity itself is immaterial and intangible, that same product and the same concept of creativity need a system of tangible resources through which to express themselves, to spread, be disseminated and even sold. In this sense it becomes easier to understand the concept of the art firm as a container and distributor of immaterial assets. The challenge for the city today is therefore embodied by entrepreneurial systems to produce and deliver culture with a high added value. In these terms the added value derives from new consumer flows towards knowledge and the symbolic system of the intangible. Traditional consumption models have revealed their limitations and cities inevitably reflect the consequences: the creation of competitive advantage for cities will therefore be the result of their capacity to contain and attract firms with a high symbolic value, like those linked to contemporary art.

$\square$ What a city has to offer will therefore be associated with these symbolic systems that communicate a sum of values: contemporary art acquires strategic value for the competitiveness of individual cities.

Each local system should have a widespread capacity to attribute sense and value to cultural experiences. The economic significance of contemporary art in the development processes of today's cities can be found in their role of catalyst of new increasingly intangible methods of producing and consuming goods and services. This consideration, applied to groups of local organisations that are oriented to contemporary art, like clusters or 'creative cities', makes sense if these groups are backed up by a strong entrepreneurial capability, an evolved form of tutelage and joint promotion of the products of the local system and their experiential value, and a capacity to produce and circulate innovative artistic ideas. When these dimensions merge, the activities to promote a city's culture acquire a social and a productive significance, while cultural activities themselves contribute decisively to the definition of the collective identity and of the symbolic capital of the local urban system (Landry, 2000). In a scenario in which competitive capability is linked increasingly to an orientation to innovation, the role of culture is to act as a synergetic agent that supplies the other sectors of the production system with content, tools, creative processes and added value, in terms of symbolic value and identity. This does not imply a negation of the economic value created by the cultural cluster as such, but underlines that the latter could have its raison d'être in the absence of this economic value.

$\square$ For example, the factor that links the cities that lead the new global economy does not derive simply from the fact that they are the financial centres of the world economy, but also from the fact that they are centres of cultural excellence, thanks to the presence of cultural entities 
like museums or theatres, and to the creative atmosphere that these enterprises create in specific clusters (Florida, 2002). Art and culture have therefore become closely connected to the economic prosperity of our urban centres (Scott, 2000; Zukin, 1995).

Even if the direct impact on the economic development of art as a generator of jobs and a source of income is not particularly significant, the symbolic and immaterial value of the contemporary work of art is growing considerably in terms of appeal for businesses, and as a factor to boost a city's cultural image.

$\square$ Some studies show that contemporary art galleries, museums and some influential artists have contributed significantly to the reinforcement of a city's image, attracting international tourist flows and global talents (Evans, 2003; Lazzeretti, 2003; Plaza, 2006; Rantisi and Leslie, 2006).

Museums, festivals, galleries, biennials and art fairs are considered enterprises in every way and described as 'cultural firms' in literature. So they play a very important role in connecting people who were previously described as 'creative' (artists, collectors, consumers/exploiters of culture, etc.) and 'non-creative' people (tourists, residents, etc.), directly or indirectly interfering in the distribution of cultural knowledge, even that specifically linked to contemporary art.

\subsection{The Potential of Contemporary Art Firms in Urban Regeneration}

One of the most important strategies of industrialised countries in the evolution of the global economy was the implementation of urban regeneration programmes. From this perspective there are various objectives, which include: radical restructuring of specific areas, environmental planning, the creation of job opportunities, the attraction of foreign investment and an increase in the quality of life of the population. History shows that one of the most important approaches to urban regeneration is to exploit the potential of the cultural sector. We have seen that culture represents a crucial point from which opportunities emerge that are not only economic, but also, and above all, linked to the opportunity for a change of identity in the transformation of the city. The creation of cultural circuits essentially implies the diversification of artistic-cultural firms and of infrastructure and a revamped image of the town. Where this approach is concerned, the development of modern and contemporary art enterprises, such as museums, has been crucial, particularly in the last three decades. This trend, which is valid all over the world, has produced numerous advantages, which range from the creation of art centres incorporating space for complementary activities, districts of galleries, districts of residences and studios for artists, right down to more specific art museums. Taking as given that these museums were not conceived with the sole objective of urban regeneration but were created and developed as starting points for more extensive development strategies, today they are an integral and essential part of every relevant regeneration plan. There can be no doubt that continuous, long-term planning is necessary to create and manage a 'large museum' worthy of 
international renown and recognition for its ability to represent the new multifunctional significance of urban regeneration.

Several cities are investing in these 'flagship developments', in other words, projects that are catalysts of regeneration, and can be justified by the fact that they attract investment. The concept was defined by Smyth (1994:34) as 'a development in its own right, which may or may not be self-sustaining; a marshalling point for further investment and a marketing tool for an area or city'.

In a city that is striving to create new economic conditions, every additional investment is very welcome but, what is even more important, when the first objective of the regeneration of a city is to change its image, it is clearly essential to use specific tools. Emblematic buildings such as contemporary art museums can also be considered in the light of the particular political situation in the region or the city. For example, in a region where ethnic identity has a certain significance at a private and a government level, a visual reminder of its specific nature expressed in a representative form, could be a reference point but also a source of civic pride.

$\square$ The project to launch a new 'extraordinary' contemporary art museum in the city of Milan was exploited in the outdoor advertising for the 'Moratti for Milan' election campaign of 2011.

Successful examples of market-oriented cities, those whose policies and strategies tend in this direction, can be a good point of reference for cultural planning that aims to increase a city's economic potential.

$\square$ The Guggenheim Museum in Bilbao, Spain, is the fruit of a publicprivate partnership. It was created in the spirit of an emblematic building that could pave the way for the development of subsequent projects, attracting foreign investment to the cultural area it created, while also projecting the city's artistic image all over the world. What is more, where the concept of ethnic identity is concerned, the Guggenheim Bilbao was not only the product of the Guggenheim firmfoundation's management policy, but also the product of Basque aspirations ${ }^{1}$.

Most city regeneration projects that have exploited the creation of a new museum as the main element of their cultural development have tended to opt for a modern, or more recently, a contemporary art museum. This is not casual and there are numerous reasons for it. If we overlook those related more to the museum and its content (what and how we define as 'culture', etc.) one important reason is the fact that urban regeneration plans need dynamic projects that are able to represent change, the modern day, progress and competitiveness. In our perception of the demand to exploit art and culture, any art predating the 20th century is considered old fashioned and of a low level, regardless of its aesthetic value (Baniotopoulou, 2001). So it certainly cannot be associated with the idea of progress. 
$\square$ Museums and contemporary art centres, like foundations, can in this sense be considered ideal because this type of art embodies 'the spirit of modernisation: an avant-garde vital to the development of society as a whole and thus in the interest - in the end - of all people' (Vaessen, 1993:32).

Very often new centres of contemporary art are named after the donors of the works or after private collectors. As a result, the 'name' can be a strong distinguishing element of a project but at the same time a factor of attraction for investment. Many contemporary art collections that are entirely or partly contained in museums are eponymous. The names add value to the museums and the space they occupy, not only for their importance in relation to the art market, but also because they amplify its importance in terms of public appreciation (and this reflects once again on the growing importance of immaterial consumption). This trend is strongly highlighted by the fierce international competition between modern and contemporary art museums as undisputed poles of attraction for tourists. Since the 1990s a great deal of attention has been focused on the relation between museums and the public, which is considered a 'consumer' for the first time (Wood, 1993).

$\square$ From this perspective, the Guggenheim museum meets the needs of a city like Bilbao perfectly. The city was trying to emerge economically, and thanks to the museum it has succeeded in reaching its set target, exploiting a collection with an internationally recognised name, in addition to the construction of a building with a strong aesthetic-visual impact (Baniotopoulou, 2001; Rodriguez and Vicario, 2005; Plaza, et al., 2010).

On the business side, encouraged by a favourable general climate, the Guggenheim Foundation grasped the opportunity to launch its own franchising activities. Many of the contemporary works of art exhibited in these centres are produced by living artists-celebrities, who are in tune with a sort of popularisation of art, driven by the artists themselves or by the gallery owners, museums or auction houses that represent them or sell their work.

a Maurizio Cattelan or a Damien Hirst will bring publicity, both positive and negative, to any container, exhibition or sale, which will certainly generate an increase in visitor numbers or purchasers and therefore in revenues.

There is another reason that can explain this preference for contemporary art when there is a propensity for the creation of a similar museum, or for an event or an artist. The public notoriously considers contemporary art as an intimidating experience, and this is probably because the enjoyment of contemporary art has always been considered elitist. As a result, the artist himself primarily addresses a public of experts, ignoring the needs of all the rest of the audience. Contemporary 
art has always been branded as incomprehensible (except by professionals or experts in the field), and this diffidence on the part of the broader public towards a type of art that is often considered impenetrable means that a form of art that is only 'comprehensible' to a few can become a political tool of power. In other words, the harder something is to understand, the easier it is to impose it: this probably results in greater autonomy in the strategic decisions taken by a local authority regarding a collection or urban furniture. It therefore seems evident that because it is part of plans to revamp and regenerate the city, the tendency towards the creation of contemporary art centres and museums, is generated first and foremost by market considerations, or by political reasons, and is strengthened by the current global economic situation and the context in which contemporary art is moving. The link between contemporary art firms and the territory could therefore develop according to the following considerations. First of all, because of the stratification of contemporary art, or better still, of its market, including businesses and players, public sector enterprises must evolve beyond their traditional role of financiers and try to achieve a more complex role related to strategic and operational support. Secondly, culture and contemporary art create a production and distribution system with numerous economic, financial and social facets, which could represent a possible reference not only for the cultural scene but also for all the other economic sectors of particular informative significance for which traditional forms of interaction are revealing huge limitations today. We have already seen that contemporary culture and art are able to generate a strong impact in economic terms, boosting the well-being of the community and the individuals who inhabit it, through the creation of a new relationship between areas of everyday life and the quality of life, reinforcing the identity of spaces that attract business and economic activities, and finally satisfying subjective needs. We can therefore maintain that production companies and the creative processes of contemporary culture reveal a new relationship between players and artisticcultural organisations, and society as a whole, rethinking the entire system of needs and values in favour of creativity and of intangible assets and consumption.

\section{Bibliography}

Baniotopoulou Evdoxia, Art for Whose Sake? Modern Art Museums and their Role in Transforming Societies: the Case of the Guggenheim Bilbao, in Journal of Conservation and Museum Studies, November, 2001, pp. 1-5.

http://dx.doi.org/10.5334\%2Fjcms.7011

Brondoni Silvio M., Intangibles, Global Networks \& Corporate Social Responsibility, Symphonya. Emerging Issues in Management (www.unimib.it/symphonya), n. 2, 2010, pp. 6-24.

http://dx.doi.org/10.4468/2010.2.02brondoni

Codignola Federica, Global Markets and Contemporary Art, Symphonya. Emerging Issues in Management (www.unimib.it/symphonya), n. 2, 2006, pp. 73-93.

http://dx.doi.org/10.4468/2006.2.06codignola

Codignola Federica, The Art Market, Global Economy and Information Transparency, Symphonya.Emerging Issues in Management (www.unimib.it/symphonya), n. 2, 2003, pp. 73-93. http://dx.doi.org/10.4468/2003.2.07codignola 
Corniani Margherita, The Cost of Managing Intangibles in Global Markets, Symphonya. Emerging Issues in Management (www.unimib.it/symphonya), n. 2, 2010, pp. 52-66.

http://dx.doi.org/10.4468/2010.2.05corniani

Evans Graeme, Hard-branding the cultural city - from Prado to Prada, in International Journal of urban and Regional Research, vol. 2, n. 27, 2003, pp. 417-440.

http://dx.doi.org/10.1111\%2F1468-2427.00455

Florida Richard, The Rise of the Creative Class. New York: Basic Books, 2002.

Gordini Niccolò, Market-Driven Management: A Critical Literature Review, Symphonya. Emerging Issues in Management (www.unimib.it/symphonya), n. 2, 2010, pp. 95-107.

http://dx.doi.org/10.4468/2010.2.08gordini

Landry Charles, The Creative City: A Toolkit for Urban Innovators. London: Earthscan, 2000.

Lazzeretti Lucia, City of art as a high culture local system and cultural districtualization processes: the cluster of art restoration in Florence, in International Journal of Urban and Regional Research, vol. 27, n. 3, 2003, pp. 635-648. http://dx.doi.org/10.1111\%2F1468-2427.00470

Plaza Beatriz, On Some Challenges and Conditions for the Guggenheim Museum Bilbao to be an Effective Economic Re-activator, in International Journal of Urban and Regional Research, vol. 32, n. 2, 2008, pp. 506-517. http://dx.doi.org/10.1111\%2Fj.1468-2427.2008.00796.x

Plaza Beatriz et al., Arte y economia, in matrimonio de conveniencia: el museo Guggenheim en Bilbao, in Scripta Nova, vol. 14, n. 335, 2010.

Porter Michael, Clusters and the new economics of competition, in Harvard Business Review, NovDic, 1998, pp. 111-128. http://dx.doi.org/10.1016\%2FS1062-9769\%2899\%2980107-0

Rantisi Norma, Leslie Deborah, Branding the design metropole: The case of Montreal, Canada, in Area, vol. 38, n. 4, 2006, pp. 364-376. http://dx.doi.org/10.1111\%2Fj.1475-4762.2006.00705.x

Rodriguez Arantxa, Vicario Lorenzo, Innovacion, Competitividad y Regeneracion Urbana: los espacios retoricos de la ciudad creativa en el Nuevo Bilbao, in Ekonomiaz, vol. 58, n. 1, 2005.

Salvioni Daniela M., Intangible Assets and Internal Controls in Global Companies, Symphonya.Emerging Issues in Management (www.unimib.it/symphonya), n. 2, 2010, pp. 39-51. http://dx.doi.org/10.4468/2010.2.4salvioni

Smyth Hedley, Marketing the City. London: E \& FN Spon, 1994.

Throsby David, Economics and Culture. Cambridge: Cambridge University Press, 2001.

Vaessen Jos, The inflation of the new: art museums on their way to the 21 st century, Boekman Foundation (ed.) in Art Museums and the Price of Success, Boekman, 1993.

Wood James, Citizens or consumers: today's art museum and its public, in Boekman Foundation, Art Museums and the Price of Success, Amsterdam: Boekman Foundation, 1993.

Zukin Sharon, The Cultures of Cities. Oxford: Blackwell, 1995. 


\section{Notes}

${ }^{1}$ See Baniotopoulou Evdoxia, Art for Whose Sake? Modern Art Museums and their Role in Transforming Societies: the Case of the Guggenheim Bilbao, in Journal of Conservation and Museum Studies, November, 2001. 